NBSIR 81-2443

\title{
Plan for A Round Robin of Hot Boxes
}

September 1981

Issued February 1982

Prepared for

National Bureau of Standards

Office of Energy Programs

Washington, DC 20234

and

U.S. Department of Energy Building Energy Science Branch

IUU

Washington, DC 20585

.456

$31-2443$

1901

c. 2 



\section{PLAN FOR A ROUND ROBIN OF HOT BOXES}

Erv L. Bales

September 1981

Issued February 1982

Prepared for

National Bureau of Standards

Office of Energy Programs

Washington, DC 20234

and

U.S. Department of Energy

Building Energy Science Branch

Washington, DC 20585

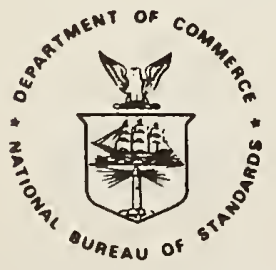

U.S. DEPARTMENT OF COMMERCE, Malcolm Baldrige, Secretary NATIONAL BUREAU OF STANDARDS, Ernest Ambler, Director 


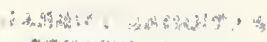

por

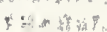

$\therefore$. 
$\underline{\text { PAGE }}$

I. $\quad$ INTRODUCTION $\ldots \ldots \ldots \ldots \ldots \ldots \ldots \ldots \ldots \ldots \ldots \ldots \ldots$

II. NEED FOR ROUND ROBIN......................... 3

III. $\quad A S T M \quad R O L E \ldots \ldots \ldots \ldots \ldots \ldots \ldots \ldots \ldots \ldots \ldots \ldots \ldots$

IV. $\quad$ PAST ROUND ROBINS ....................... 5

V.

VI. $\quad$ POSSIBLE TEST SPECIMENS.................. 9

VII. $\quad$ NUMBER OF SPECIMENS .................... 12

VIII. $\quad \operatorname{TEST}$ CONDITIONS ....................... 13

IX. $\quad$ POSSIBLE CONCERNS....................... 14

X. NBS ROLE.............................. 15

XI. $\quad$ SCHEDULING.......................... 16

XII. $\quad \operatorname{EXPECTED}$ RESULTS ....................... 18

XIII. $\quad$ RECOMMENDATIONS...................... 19

XIV. $\quad$ REFERENCES........................... 21

XV. $\quad$ APPENDIX..........................

1. Task Force Membership 22

2. Data Reporting Form 23

3. Fact Sheets on Calibrated Hot Boxes 24

4. Attendance at NBS Workshop 32

5. Parallel Heat Flow Flanking 35 

The emphasis on energy conservation because of the steep rise in oil prices since 1973 has created a need to more accurately specify the thermal performance of typical, composite building sections. The standard, steady-state, series/parallel, one-dimensional analytical models (Reference l) are not precise enough to make the needed evaluations of competing energy conservation techniques in building construction. The recent, more sophisticated extensive computer models, such as DOE-2, require more accurate data on wall systems under dynamic conditions for their use and verification. Improved apparatus to test composite non-homogeneous sections have been constructed and system data is becoming available.

The first family of such apparatus was the guarded hot box. It is in wide use and there is an ASTM Standard Test Method (Reference 2). The apparatus has an electrically heated metering box placed on the center of the test specimen with a surrounding guard box. The temperature in the guard box is controlled to be the same as that in the metering box. Therefore, all energy supplied to the metering box passes through the test specimen. Another box is attached to the opposite side of the test specimen to control conditions on that side. The thermal conductance is the net rate of energy supplied divided by the area and temperature difference across the specimen. The net rate of energy accounts for energy transferred through the guard box walls and any flanking losses around the test area.

When testing full-scale building sections, however, the apparatus becomes impractically large because of the additional. necessary guard area. There are further limitations on the guarded box which are listed by Sclvason (Reference 3): (a) the metering box interferes with the convection over the test wall, so that forced convection must be resorted to and this may give film coefficients different from those occurring in practice. It is difficult to produce equal coefficients for the metering area and the guard area, so that lateral heat transfer may occur from the measuring area to the guard area. (b) the metering box placed over the central portion of the test wall measures only the heat flow into that portion, but it has been shown by G.O. Handegord and N.B. Hutcheon that this is not necessarily the average heat flow for the whole test wall, particularly for walls containing vertical air spaces; blocking of air spaces in the test area may change the conductance substantially. (c) Radiation exchange is indefinite, and it is difficult to produce the same effect on both the metering area and the guard area of the test wall. Differences in the radiant exchange from the inner and outer surfaces of the metering box may require that different air temperatures be provided in the test box and the guard box in order to maintain zero heat flow across the test box walls and this may lead to lateral heat transier in the test wall. (d) in many cases, the metering box will not cover a representative complete module of the test. wall. 
With these limitations in mind, Solvason, of the National Research Council, Canada (Reference 3) designed the first calibrated hot box to meet his stated requirements.

"First, it was designed to meter the heat. flow into the whole of representative sections of building walls, and second, to expose the test wall to controlled temperature surroundings as well as to air at controlled temperature. Third, it was built to operate without forced air circulation over the warm side of the test wall in order to produce warm-side film coefficients approaching those in practice. Fourth, it operates with the cold-side temperature either constant or varying according to some predetermined cycle."

The box was built and used for a period but now appears to be inactive.

There was approximately a fifteen (15) year lag before another such apparatus was built by Owens-Corning Fiberglas Corporation (Reference 4). Since then, five others have been built and another is under design and construction. See Appendix 5 for brief fact sheets on these boxes. Papers have been presented on the design of six of the boxes. (References $4,5,6,7,8$, 9 , and 10). 
The calibrated hot box is a relatively new apparatus; the first of the presently operational boxes was reported in 1974 (Reference 4 and Appendix 3). The ASTM C16 Committee on Thermal Insulation has issued a draft Standard Test Method for consideration by its members. There are six boxes operational and more is expected to be within six months. As the boxes are being calibrated and used, it has been found that there are differences in results that cannot be satisfactorily rationalized. There is an immediate need to know if those differences are due to errors in measurement or inherent errors in the present design of the calibrated hot boxes. As a standard calibration specimen is not available, it is difficult to sort out the sources of the differences.

Also, the ASTM Standard Test Method is required to have a precision and accuracy statement. As each laboratory has limited experience, it has been difficult to compare results and define the expected performance.

A round robin of the calibrated hot boxes and guarded hot boxes would accomplish:

1. A determination of the resulting differences in measurement of thermal performance of a common specimen.

2. An indication of the magnitude of the precision and accuracy of the present boxes.

3. Inform each laboratory on a confidential basis how it is doing relative to all other laboratories.

4. Provide a forum for an exchange of ideas and information among laboratories.

5. Indicate by analysis of the results how the apparatus might be improved.

6. Possibly indicate operational errors.

7. Evaluate calibration procedures in the present draft AsTM Standard Test Method. Included would be the examination of the extrapolation of calibration at one measured thermal resistance to higher thermal resistances. 
The ASTM has taken on the task of the writing of a Standard Test Method for the calibrated hot box. The Cl6 Committee on Thermal and Cryogenic Insulating Materials has assigned that responsibility to the C16.30 Subcommittee. Thermal Measurements, chaired by Mr. Charles Pelanne. A task force headed by Mr. Marion Hollingsworth has written the drafts. Out of the task force work and other discussions, a workshop was held at the National Bureau of Standards (NBS) to discuss the state-of-theart. It was attended by representatives of each organization with calibrated hot box and those others interested; the attendance list is Appendix 4. As the meeting progressed, it became evident that a round robin would help resolve many of the issues discussed.

At the following C16 meeting in San Diego on April 20-23, 1979, a task force for the hot box round robin was appointed. A list of the present members is Appendix 1.

Subsequently, the Department of Energy funded the initial effort to plan the round robin by the NBS for ASTM. This was done to shorten the time, as the Department of Energy is vitally interested in seeing data on building composite sections published.

This report is the result of the planning effort. The task force herein describes the conduct of the round robin for approval by the cl6.30 subcommittee. It is expected that the subcommittee will oversee the testing program, report the results, and continue to provide a forum for the discussion of hot box testing. 
In planning a round robin, it is natural to examine the experiences of past efforts. In searching the literature and talking to those active in thermal measurement, there appears to have been only three round robins on thermal insulation reported, one limited round robin conducted by an insulation company to be reported soon; one currently underway which is being sponsored by ASTM C16.30 Subcommittee and the Mineral Insulation Manufacturers Association (MIMA); and an internationaI round robin in the planning stage which is sponsored by the International Standards Organization (ISO), Technical Committee 163 on Thermal Insulation. A review of the planning and results are summarized below:

1. "Interlaboratory Comparison of Thermal Conductivity Determinations with Guarded Hot Plate" H.E. Robinson and T.W. Watson (Reference 11).

a. Specimen - corkboard, one inch thick, 18 specimens at a density of 7.3 pef and 2 specimens at a density of 13.3 pcf.

b. Specimen number - one for each apparatus, total of 20. Because of the wide range of plate sizes and the number of laboratories participating, it was considered not feasible to circulate one set of specimens.

c. Mean temperature - two or more requested between 20 and $1300^{\circ}$. Data presented all show three mean temperatures.

d. Specimen reference - After testing, all specimens cut down and sent to NBS for reference testing. The cutting caused change in average density, presumably because of non uniformity in the specimen material.

e. Results - Data indicate practical value of CI77-45. Difference among the apparatus were pointed out. The actual data are given with an analysis.

f. Time - the program took between two and five years. This is an estimate as the dates were not explicitly reported.

2. "International Comparative Measurements of Thermal Conductivity" (Reference 12).

a. Specimen - The criterion for selection of a material were "that it should have a stable and uniform conductivity over the whole area of a large slab and that a batch of slabs with closely similar thermal properties can be obtained. It should be unaffected by environmental conditions during transport and testing, and also tha conductivity value should not depend upon the orientation of the test equipment. 
A semi-rigid resin-bonded glass fiber board was used, density being about 5.5 pcf".

b. Number of specimens - "It was decided for several reasons (not the least being the differing sizes of apparatus) that samples should not be circulated from laboratory to laboratory, but that they should be individual, all emanate from one consignment of material and be sent out from one source". There were twenty-two (22) specimens.

c. Mean temperatures - Testing was requested at 32,50 and 680F mean temperatures.

d. Specimen reference - National Physical Laboratory prepared the samples and made tests on a number of samples over a wider temperature range. The samples were sent without the reference value from National Physical Laboratory.

e. Results - Improved design and operation of several apparatus. The reduction in differences from the National Physical Laboratory reference data was from five percent to one percent after changes had been made in several laboratories. Two laboratories chose to construct new apparatus which resulted in the reduction of the difference to one percent. Several sources of error are listed.

f. Time - A committee was formed in June 1961; the report is dated 1968. Therefore, the time for the round robin was about seven years.

3. "An Interlaboratory Comparison of the ASTM C355 Pipe Insulation Test", M. Hollingsworth, Jr. (Reference 13).

a. Specimen - Resin-bonded glass fiber at a density of approximately 6.5 pcf. The round robin was not planned, but grew out of testing by two laboratories. There was no attempt to select a material based on a set of criterion.

b. Number of specimens - There was one specimen tested by two laboratories. As participation was extended to others, a second specimen was added. Both specimens were tested by ten laboratories.

c. Mean Temperatures - The range of mean temperature was 120 to $3000 F$. Each laboratory ran at least three mean temperatures, and generally more.

d. Specimen reference - Laboratory 1, the originator, acted as the distribution center ard conducted several sets of tests on the specimen. 
e. Results - The data were within \pm three percent of the mean value. There was degradation of the specimen, probably due to handling durjng shipping and testing.

f. Time - The total time for the round robin was seven and one-half years and involved ten testing laboratories.

4. ASTM and MIMA-sponsored round robin currently underway (Reference 14).

C. Pelanne is managing the effort in two phases. In the first phase, a one-inch specimen of fiber glass is being circulated among the participants. This phase was begun by MIMA to determine the reproducibility of testing low density fiber glass with the guarded hot plate. Pelanne reported preliminary results of three laboratories at an ASTM C16.30 meeting in San Antonio. ASTM was added as a co-sponsor. Several preliminary reports have been made, but the final report has not been given yet, almost three years later. In this round robin, a determination of the precision measurement was the primary objective. It was, therefore, necessary to have only one specimen.

At the ASTM Albuquerque meeting in May, 1978 Phase II was added. The objective was to determine the precision of use thickness testing. The test specimens were to be $3-1 / 2,6$ and 8 inches. New specimens were prepared and testing was expected to begin about June 1978. This work has not been reported.

5. Jim walter Research Corporation has conducted a companyspcnsored round robin on their product with two other laboratories using the guarded hot box. The results were presented in December 1979 at the ASHRAE/DOE Conference (Reference 1j).

6. International Interlaboratory Comparison of Themal Conductivity Determinations with a Guarded Hot Plate and Heat Flow Transducers.

This ISO 163 sponsored round robin is underway. Thus far 22 countries woridwide have volunteered to participate with 122 measurement instruments. It is planned to have measurements made on dense glass fiber board ( 10pcf). low-density glass fiber blanket $(\sim 0.6$ pcf $)$, a closed cell plastic insulation, and an aif gap. A working group from ISO 163 chaired by Frank Powell of NBS will conduct the round robin. Under consideration are measurements to be made at three mean temperatures, several thicknesses of material, and if feasible, a density range. The round robin will be operated with several "loops" running simultaneously, e.g., a North American Loop, etc. Specimens will be circulated in series to about 6-10 laboratories in each loop. The round robin started in 1981 . 


\section{OBJECTIVES}

Decisions on the design of the round robin are based on the objectives. The objectives can either be related to the apparatus or to the test specimen. In the latter case an attempt is made to. resolve differences in reported data in thermal properties for an apparatus that has been in use for some time and is well accepted. In the former case, the present one, the round robin is used to improve the apparatus. Accordingly the objectives are as follows in priority order:

1. Alert all concerned to the possibility and sources of significant errors in design and operation or measurement of hot boxes, with emphasis on the calibrated hot box.

2. Evaluate and improve calibration procedure. Develop standard calibration procedure.

3. Provide present and future operators with confidence in their apparatus and a basis on how their box performs compared to all others.

4. Provide information for the overall improvernent of hot box ASTM Standard Test Methods, particularly data for the writing of a precisjon and accuracy statement.

5. Compare the measured thermal conductance of various specimens from the lot of material produced for the round robin for possible development of a reference material. This will include results from the guarded hot box apparatus that participate and from the guarded hot plate testing of samples of the test specimen.

6. Provide guidelines to improve design of future hot boxes. 
The thermal insulation selected for the test specimen depends on the objectives of the round robin. For this round robin the primary concern is with the development of an apparatus and not the establishment of a reference material. It is important that the specimen be simple in construction. The issues to be considered in the selection are:

1. Should the specimen be homogenous of one material or non-homogenous similar to normal construction? As it is imperative that data be comparable among the laboratories, the specimen should be as similar for each laboratory as possible. The specimen should have a negligible influence on any differences between two laboratories or between one laboratory and the mean values. The draw back to normal construction using wooden members is the non-uniformity of wood and the difficulty in controlling moisture changes from one laboratory to another.

2. What are restrictions on material properties? The specimen will range in size from $14 \times 20$ feet to about $6 \times 6$ feet for large calibrated boxes and to smaller sizes for the guarded hot boxes. It must be mechanically strong enough to stand alone in this range of sizes and it must be stable with time. The specimen properties must not change with time or handling. It should also be impervious to air and moisture. Large quantities should be reasonably uniform in property values (particularly thermal conductance and density) and in thickness.

3. What thermal. resistance should be tested? It would be desirable to test at several thermal resistance values to determine performance characteristics over the full testing capability of the apparatus. More than one value seems impractical at present due to the testing time required. Problems with the operation or design are likely to occur at the larger $R$ values. In addition, industry and government are recommending higher values in actual applications. Therefore, the specimen should be in the range of $R=15$ to 20 .

4. How much material is needed? For the calibrated hot boxes identified, see Appendix 3, there is 884 square feet of testing area. The six largest guarded hot boxes listed in Appendix 3 have a total sample area of 465 square feet. The total area is 1349 square feet. To allow for all other guarded hot boxes to participate and for some contingency, at least $50 \%$ should be added which results in a total area of about 2000 square feet. If there is a specimen for every laboratory, then 2000 square feet of about $R=20$ material will be required. 
5. What insulation material should be used? There are several possibilities. If non-hornogeneous specimens are ruled out, the specimen can be either of one monolithic material or a single insulation material. with skins to provide the necessary structural strength and stability. The following are the insulation materials that were considered:

a. Fiber glass board - This material has recently been established as a standard reference material by NBS and has been used in one previous round robin. It has a thermal resistance of around 4 per inch. Owens-Corning Fiberglas Corp., a previous supplier, has enough material on hand for one test specimen. Another lot of material would have to be made for this program if all laboratories receive a specimen. It can be made in $4 \times 10$ feet boards. For the higher $R$ value suggested earlier two layers of 2 inch material would have to be l'aminated together with a non-penetrating contact cement. A skin would also need to be laminated to prevent air and moisture from passing through the specimen while testing.

b. Extruded polystyrene - This material has an $R$ value per inch of about 5 but there is some concern with the stability of the thermal conductance with time. DOW Chemical, USA, has been able to age and stabilize the material by holding it at 145 of for six months. Dow has enough material on hand for one test specimen. Another lot of material would have to be made for this program if all laboratories receive a specimen. DOW considers it impractical to supply the quantity required for all laboratories due to the aging process. For the high $R$ values two layers of 2 inch sheets would have to be laminated together. As manufactured, the material is impervious to air and has a low water vapor permeability of about 0.6 perm-in.

c. Molded polystyrene - This material has an $R$ value per inch of about 4. As manufactured the density variation is about $10 \%$.

W.R. Grace and Company has run a controlled production of seven billets at 1.25 pcf density. The billets were characterized for density as a function of position and for conductivity as a function of density. By using the middle section, the billets' density was maintained within a $5 \%$ variation.

A specimen can be made in one four inch slab which would eliminate any lamination. The material is impervious to air and has a water vapor permeability of about 1.2 perm-in. It is recommended that the surface be coated with a layer of adhesive, one coat of primary and two coats of light colored latex base paint. A 90 lb. Kraft paper facing was not satisfactory due to shrinkage. 
d. Low-density fiber glass - This is the material most often used in new residential construction and it has an $R$ value of about 3 per inch. It is being used by the NBS program for laboratory accreditation. It would be useful to have the round robin use the same material although that is not an objective of the program. NBS has about 1500 square feet on hand which means that only one specimen could be supplied. The material is available in 1 inch $4 \times 4$ foot sections. To make up large specimens of $R=20$ material would require 6 layers laminated together. It would probably be mechanically weak and unstable. 
There are two extremes in the number of specimens required for a round robin. One is to use a single specimen which is sent to each laboratory in turn for testing. This usually requires a rigid scheduling so that the apparatus with the largest test area receives the specimen first and it is trimmed as it is passed along. The other extreme is to provide each laboratory with its own. specimen from a single lot of suitable uniform and stable material. In the first case there is no problem with material variability, assuming that trimming causes no changes in properties, such as the average density. Results could be effected by handling damage or long term aging.

In the multiple specimen case the results must be considered in terms of the variability of the material properties within the lot of material. If the lot of material is well characterized this effect can be rationalized. On the positive side, the handling is reduced and there would be no possible damage due to trimming.

Of course, there is the intermediate case, at least one specimen tested by at least two laboracories. Of the calibrated hot boxes likely to participate, two have the same testing area, $8 \times 8$ feet; in addition one guarded hot box has the same sample area. There are also two guarded hot boxes with a sample area of $6 \times 6$ feet. If all participate and their scheduling can be worked out for multiple specimen testing, an exchange of specimens by the laboratories with the same area would add significantly to the results of the round robin. 
To make the measurements directly comparable the test conditions must be specified and reported in a stanaard format. A sample data sheet is given in Appendix 2 for possible use in the round robin.

The following are the variables to be specified:

1. Mean temperature of specimen, ${ }^{O_{F}}$.

2. Temperature difference across specimen, ${ }_{F}$.

3. Room Temperature in which box is located, OF.

4. Relative humidity on both sides of specimen, \%

5. Pressure difference across specimen, inch of water.

One least one mean temperature will be specified and two others suggested if scheduling permits an organization to do the testing. A 450F mean temperature is one that all boxes can attain with a 40 or $500 \mathrm{~F}$ temperature difference, although $750 \mathrm{~F}$ is the usual mean reported for insulation materials (See Reference 1 ). In addition a $950 \mathrm{~F}$ mean is usually taken to represent summer conditions.

The room temperature is important as the temperature difference across the measurement box walls is directly proportional to the heat loss.

In most boxes the relative humidity cannot be controlled at a preselected high value but it can be maintained at a relatively low value. A low relative humidity is necessary to keep Erost off the cooling coils or heat exchange fins on the cold side. The specification should be such that normal operation will easily meet the condition.

It is important that relative humidity be measured and reported as a water vapor gradient in the specimen material could cause significant effect on the measured thermal conductance.

The pressure difference should be as close to zero as practical. Any pressure gradient could cause an infiltration of air across the specimen and a resultant transfer of energy. It is important that the pressure difference be measured and reported. 
Experience with the calibrated hot box is limited but some anomalies have appeared. It is expected that the analysis of the round robin data will reveal others and offer explanations. The testing by the guarded hot boxes will be invaluable in this regard, as it makes an absolute measurement. The following has been observed:

1. In one laboratory the results of testing of large area, well characterized fiber glass specimens has given results different than expected from previous measurements. The difference is considered to be likely due to a flanking or by-pass loss around the specimen in the materials holding the specimen in place.

2. In another laboratory two layers of well characterized, aged, one inch extruded polystyrene with metal skins have been laminated to form a calibration specimen. Measurements in a calibrated box indicate $\mathrm{K}$ values lower than expected. The difference was thought to be due to flanking losses. Further testing of a specimen from the same lot of material in a guarded hot box has confirmed the calibrated hot box result.

3. In a third laboratory the measurements on extruded polystyrene in a calibrated hot box and in a guarded hot box have been made over a range of $R$ values. The measured $R$ values in the calibrated box tend to be higher than those in the guarded box. The difference seems to get larger with increasing $R$.

In informal discussions among operators and from computer analysis of the data the following are possible sources of error:

1. Flanking or by-pass heat transfer around the specimen, through the materials holding the specimen within the holding frame.

2. The extrapolation of calibration results at one or two $R$ measurement to higher values.

3. A weakness in a calibration procedure using the temperature difference between the measurement box and the room.

Appendix 5 offers an example of a simple parallel heat flow model to make an estimate of the heat transfer through $1 / 2$ inch thick plywood used to mechanically hold a specimen in place. It indicates for an $\mathrm{R}=15$ specimen a sizeable flarking of about $5 \%$ of the total heat transfer. 


\section{NBS ROLE}

The role of the National Bureau of Standards is to provide guidance and leadership in measurement technology and to dispense reference materials used by the measurement community. In addition, it acts as a referee in situations where a difference occurs in measured results on the same material. In the present case, a new test method and apparatus, the calibrated hot box, is being developed and the bureau is building its own facility and will participate in the development process, including the round robin. NBS will be in a position to make improvements and to mediate any disputes. In adaition, it would be possible to extend the accreditation program to this apparatus when the test method appears on the ASTM books.

The Bureau has taken the responsibility to plan and conduct a round robin for ASTM C.16.30. This will require the following:

1. Take the responsibility to physically and statistically characterize the specimen material in terms of its density, thermal conductance, and thickness. These measurements would be done at the Bureau and/or other places under its supervisjon.

2. Establish a repository for the specimen material.

3. Ship the materials to the participating laboratories. If the materials move from one laboratory to another, make sure schedules are followed.

4. Analyze the resulting data.

5. Report the final results in a manner that keeps each laboratory's identity confidential.

It is expected that the NBS would work with the supplier of the specimen material and that the DOE would continue its support. The DOE is vitally inierested in establishing the performance of building envelopes under steady and dynamic conditions. Energy conservation depends on knowing accurately how buildings lose energy. 
It is desirable that the total time for round robin be as short as possible, on the order of a year or less. The time for previous round robins has been very long, ranging from three to eight years. In the following a time projection is made for the two extremes of one specimen passed to all laboratories in sequence or a specimen for each laboratory.

It is expected that all laboratories with a calibrated hot box will volunteer to take part in the round robin and each is represented on the task force. In addition those laboratories with guarded hot boxes with large sample areas will be encouraged to take part. Others may also participate if they request specimen material. All laboratories that are known to have hot boxes will be informed that a round robin is beind conducted. The primary effort and the impelling reason for the program is to test a single material in the calibrated hot boxes. A preliminary report will be issued when all testing has been finished in the calibrated hot boxes and the large sample area guarded hot boxes.

The operators of the calibrated hot boxes estimate about two weeks time to mount a specimen and measure its thermal conductance at one mean temperature. About one month advance notice is needed to schedule time in the apparatus. It is estimated that time for a guarded box would be similar.

There are two known calibrated hot boxes and one guarded hot box with 8 x 8 foot specimen areas. As pointed out, it would be of great value if the specimens could be exchanged and rerun. In addition, there are two guarded hot boxes with $6 \times 6$ foot specimen areas, they could also exchange.

Based on these considerations the following time estimates have been made:

1. One.specimen circulated to all laboratories. In addition to test time an allowance would be required to trim the specimen and to package and ship it to the next laboratory. A reasonable time for each laboratory is six weeks, two weeks testing, two weeks for trimming, and two weeks for shipping. The total time is 72 weeks for twelve laboratories If 6 weeks is added for reporting, the total time is $1-1 / 2$ years.

obtaining a well characterized specimen would be negligible as only one sample is required. At least two sources have enough material on hand. 
2. A specimen for each laboratory. Each 1aboratory would need about two weeks for testing. Additional time should be allowed for scheduling and reporting, the total time would reasonably be one month. As a great deal more material is required, time should be allowed to characterize the material lot, estimated at three months. The total time may be on the order of six months.

It is expected that the results of the round robin will generate a need for more information and further testing, either on the same specimen or on other specimens, e.g., a built-up stud wall section. If each laboratory has its specimen in hand it will be somewhat easier to have further testing done.

The final report will include all data from al1 those laboratories that choose to participate and will be issued by ASTM Subcommittee C16.30. 
The "hard" results will be in two reports, the present one on planning and a final report on the results of the testing. The "soft" results will be the many discussions, formal and informal, of the many people involved in the measurements. The round robin and the task force will provide a focal point for the general advancement of the calibration hot box apparatus and thermal measurements of large, full-scale wall sections in general.

Analysis of the data will provide the basis on which a precision and accuracy statement can be made for the ASTM standard Test Method. It is likely that a single calibration procedure will evolve.

A general upgrading of measurement techniques and instrumentation is also likely when the operators compare the way data are measured and recorded. This will be an informal result, as specific instrumentation and data reduction apparatus are not specified and will probably not be cited in the final report.

The final report of the data and its analysis will state the mean values and the differences and give some incication of the types and possible sources of such differences. As each laboratory is aware of its performance compared to all others, there will be a general upgrading in performance and techniques.

Finally, the results will be useful to the NBS laboratory accreditation program when it considers the calibrated hot box. 
There are several issues on which all those who intend to participate should agree:

1. Selection of a test specimen.

2. Setting of the number of specimens.

3. Specimen R-value.

4. Test conditions of mean temperature, temperature difference, relative humidity, and pressure difference.

5. Number of test points to be run.

6. General specifications, such as adhesive to join sections of the specimen, material used to seal the specimen into the frame, and the tape used to mount the surface thermocouples.

Based on the discussions in this report, the following recommendations are made:

1. The test material should be molded polystyrene. If satisfactory tolerance cannot be held in the manufacturing process, then fiber glass board should be used by laminating two 2-inch boards and a plastic skin. Owens-Corning Fiberglas Corp. can supply the material, and DOW Chemical USA, can do the laminating on their line.

2. Each laboratory should be provided with a specimen that will fit its sample area.

3. The specimen $R$-value should be a nominal $R=16$. For the recommended material, this will require a single monolithic 4-inch specimen made up of 4 foot wide sections.

4. The test conditions should be:

a. Mean temperature $=45^{\circ} \mathrm{F}$.

b. Temperature difference $=50^{\circ} \mathrm{F}$.

c. Relative humidity as low as possible on both sides of the test section. Control and research pressure difference at zero.

5. A minimurn of one test point should be run. If resources permit it, other suggested points are mean temperatures of $750 \mathrm{~F}$ and $950 \mathrm{~F}$ with a $500 \mathrm{~F}$ temperature difference. 
6. The adhesive used to join sections of molded polystyrene and the polystyrene edges to the test forms should be a one component urethane. The joint between the specimen and the frame should be sealed with a silicone rubber caulk.

7. The surface thermocouple should be mounted with the tape. Finally, it is recommended that all data should be reported on the data form in Appendix 2 . 
1. "Handbook of Fundamentals" ASHRAE, 1977.

2. "Standard Test Method for Thermal Conductance and Transmittance of Built-Up Sections by Means of the Guarded Hot Box" C236-66, ASTM.

3. Solvason, K.R. "Large-Scale Wall Heat-Flow Measuring Apparatus" ASHRAE Transactions, 65, 1959.

4. Mumaw, J.R., "Calibrated Hot Box: An Effective Means for Measuring Thermal Conductance in Large Wall Sections," ASTM STP 544, 1974, pp. 193-211.

5. Mumaw, J.R., "Thermal Research Facility -- Large Calibrated Hot Box for Horizontal Building Elements," DOE/ASTM Conference STP 718, 1980.

6. Rucker, J.L., and Mumaw, J.R., "Calibration Procedures and Results for a Large Calibrated Hot Box", ASHRAE/DOE Conference ASHRAE SP 28, 1979.

7. Miller, R.G., Perrine, E.L., and Linehan, P.W., "A Calibrated/Guarded Hot Box Test Facility," ASTM STP 660, 1.978, pp. 329-341。

8. Perrine, E.L., Linehan, P.W., Howanski, S.W., Shu, L.S.," "The Design and Construction of a Calibrated/Guarded Hot Box Facility" ASHRAE/DOE Conference, ASHRAE SP28, 1979.

9. Achenbach, E.R., "Design of a Calibrated Hot Box for Measuring the Heat. Air and Moisture Transfer of Composite Building Walis" ASHRAE/DOE Conference, ASHRAE SP 28, 1979.

10. Fiorato, A.E., "Laboratory Tests of Thermal Performance of Exterior Walls" ASHRAE/DOE Conference, ASHRAE SP 28, 1979.

11. Robinson, H.E., and Watson, W.W., "Interlaboratory Comparison of Thermal Conductivity Determinations with Guarded Hot Plates," Symposium on Thermal Insulating Materials" ASTM STP 119,. 1951, pp. $36-44$.

12. "International Comparative Measurements of Thermal Conductivity" IIR TOME XLVIII, NO. $1,1968$.

13. Hollingsworth, M., Jr., "An Interlaboratory Comparison of the ASTM C 335 Pipe Insulation Test," ISTM STP 660, 1978, pp, 50-59.

14. ASTM 16.30 Subcommittee minutes for 1977 and 1978.

15. Sherman, Morton, "Aged Thermal Resistance (R-value) of Foil-Faced Polyisocyanurate Foam Therma Insulation Board" ASHRAE/DOE, Conference, ASHRAE SP 28, 1979. 
ASTM - C16.30 Thermal Measurements Task Force - Hot Box Round Robin

1. Erv Bales, Chairman 202/252-9187

Building Energy Science Branch

Office of Conservation and Renewable Energy

U.S. Department of Energy

Washington, DC 20585

2. Dr. Anthony Fiorato 312/966-6200

Construction Technology Laboratories

5420 Old Orchard Road

Skokie, Illinois 60077

3. Mr. David Greason 614/587-4362

Dow Chemical, USA

Granville Research \& Development Center

P.O. Box 515

Granville, Ohio 43023

4. Mr. Marion Hollingsworth, Jr. 614/587-0610

Owens-Corning Fiberglas Corporation

Technical Center, Energy Measurements Laboratory

P.O. Box 415

Granville, Ohio 43023

5. Mr. Jack Howanski

6. Dr. Diana Kirkpatrick 301/921-2946

National Bureau of Standards

24408 Kakaf Drive,

Damascus, Mary land 20750

7. Dr. Gerry Miller 813/576-4171

$J$ im Walter Research Corporation

10301 Ninth Street, North

st. Petersburg, Florida 33702

8. Mr. Frank Powell 301/921-3275

National Bureau of Standards

Building 224, Room B.120

Washington, DC 20234

9. Mr. Ronald Tye 207/282-5911

Energy Materials Testing Laboratory

Biddeford Industrial park

Biddeford, Maine 04005 


\section{CALIBRATED HOT BOX}

METERING AREA =

TEST PANEL CONSTRUCTION:

SUREACE TEMFERATURE

AIR TEMPERATURE

AIR VELOCITY

SURFACE COEFFICIENT

\begin{tabular}{|l|l|}
\hline HOT SIDE & COLD SIDE \\
\hline & \\
\hline & \\
\hline & \\
\hline & \\
\hline
\end{tabular}

AVERAGE POWER INPUT =

MEAN TEMPERATURE =

THERMAL CONDUCTANCE, $\mathrm{C}=$

THERMAL RESISTANCE, $\mathrm{R}=$

THERMAL TRANSMITTANCE, $\mathrm{U}=$

THERMAL RESISTANCE, $\mathrm{R}=$

COMMENTS : 
Summary fact sheets for each known Calibrated Hot Box in the United States are in this

Appendix. In summary, table is as follows:

ORGANIZATION

1. W.R. Grace \& Company

2. DOW Chemical, USA

3. Construction Technology Laboratories

4. Owens-Corning Fiberglas

5. Owens-Corning Fiberglas

6. Jim Walter Research Corp.

7. National Bureau of Standards
SPECIMEN SIZE

REMARKS

8 ft. $x \quad 8$ ft. Can be used in Guarded mode

9.8 ft. $x 13.1$ ft.

$8 \mathrm{ft.} x \quad 8 \mathrm{ft.}$ Can test for 7 inch. dynamic testing

9 ft. $\times 14$ ft. Vertical heat flow

14 ft. $x 20$ ft. Vertical heat flow

8 ft. $x 8$ ft. Can be used in Guarded mode

10 ft. x15 ft. Can be used for dynamic, moj.sture and infiltration heating. 
1. Organization:

2. Contact Person:

3. T'est Specimen Size:

4. Temperature Range:

5. Design $\mathrm{R}$ Value:

6. Method of Temperature Control: Cold Side - external 5 hp; Refrigeration unit which supplies chilled air. Hot Side - water/air heat exchanger in box. The water flow and temperature rise are controlled.

7. Calibration Technique:

Measure a shell coefficient and

a frame coefficient so that $Q_{\text {loss }}=$

$$
C_{1}\left(T_{\text {Hot }}-T_{A M B}\right)+C_{2}\left(T_{\text {Hot }}-T_{\text {Cold }}\right)
$$

8. Specimen fixture configuration: Not firm in design at this time.

NOTE: This facility is under construction and will be ready for operation about May 1980. This facility will be able to test under dynamic conditions with a maximum rate of change of $350 \mathrm{~F} / \mathrm{hr}$ at $800 \mathrm{~F}$ heating and $20^{\circ} \mathrm{F} / \mathrm{hr}$ at $15^{\circ} \mathrm{F}$ cooling. In addition, the test section can be positioned vertically or horizontally and can be operated in the Guarded Mode. 
1. Organization:

2. Contact Person:

3. Test Specimen Size:

4. Temperature Range:
Dow Chemical, USA

Dr. David Greason

$9.84 \times 13.12$ feet $(3 \times 4$ meter)

cold side $\quad-50$ to $70^{\circ} \mathrm{F}$

Hot Side $\quad 70$ to $140^{\circ} \mathrm{F}$

5. Design R. Value:

Have tested over $R=40$

6. Method of Temperature Control: Cold side - Refrigeration unit which supplies chilled air. Controlled electrical heaters are used for fine tuning the temperature. Hot Side - SCR controlled electric heaters (three) in the box.

7. Calibration Technique:

Use thermal piles on walls to determine correction factor for the total heat

8. Specimen fixture

Specimen is built into frame inside Configuration: a 1/2" plywood skin. The seams are caulked. May eliminate plywood to reduce possible flanking losses.

NOTE: The test section may be positioned vertically or horizontally. The environment of the CHB is controlled so that the temperature difference across the hot side wall can be made nearly zero. This makes the operation somewhat similar to a Guarded Mode. 
1. Organization:

2. Contact Person:

3. Test Specimen Size:

4. Temperature Range:

5. Design $R$ Value:

6. Method of Temperature Control:

7. Calibration Technique:

8. Specimen Fixture Configuration:
Construction Technology Laboratories

Dr. Anthony E. Fiorato

8 ft $\times 7$ inches $\times 8$ ft $\times 7$ inches

Cold side Hot Side -20 to $120^{\circ} \mathrm{F}$ (Outdoor) 65 to $800 \mathrm{~F}$ (Indoor)

2 to 20

Cold side - Refrigeration controllers on cooling coils and heating elements in indoor and outdoor chambers. Heating elements SCR controlled.

Calibrate base conditions for each test run by holding ${ }^{\mathrm{T}}{ }_{\mathrm{AMB}}={ }^{\mathrm{T}}$ Cold $={ }^{\mathrm{T}}{ }_{\text {Hot }}$.

Then determine wall coefficient with: $\mathrm{T}_{\text {AMB }}=\mathrm{T}_{\text {Hot }}$ and $\mathrm{T}_{\text {Hot }}-\mathrm{T}_{\text {Cold }}=\Delta \mathrm{T}$.

Can also calibrate for $\mathrm{T}_{\text {Hot }}=\mathrm{T}_{\text {Cold }}=\mathrm{T}_{\mathrm{A} \text { MB }}$ and correct for losses.

Specimen is built into 12 -inch square urethane frame inside a 1/4" plywood skin.

NOTE: This facility has the ability to test under dynamic conditions with a maximum rate of change of 50 to $100^{\circ} \mathrm{F}$ per hour (plenum air). Rate depends on absolute value of set point temperatures. 
1. Organization:

2. Contact Person:

3. Test Specimen Size:

4. Temperature Range:

5. Design $R$ Value:

6. Method of Temperature Control:

7. Calibration Technique:

8. Specimen Fixture Configuration:
Owens-Corning Fiberglas Corp.

Mr. John Mumaw

$9 \times 14$ feet

Cold side $\quad-40$ to $58^{\circ} \mathrm{F}$

Hot side

32 to $150^{\circ} \mathrm{F}$

1 to 35

Cold Side - Direct expansion system to cold temp, reheat with 6 step electrical resistance. Heaters with on/off controller.

Hot Side - no cooling - heating same as cold side.

Measure a shell coefficient and a frame coefficient so that:

$Q_{\text {LOSS }}=C_{1}\left(T_{\text {HOT }}-T_{\text {AMB }}\right)+C_{2}\left(T_{\text {HOT }}-T_{\text {COLD }}\right)$

Specimen built into frame inside a 1/16" FRP skin. 
1. Organization:

2. Contact Person:

3. Test Specimen Size:

4. Temperature Range:

5. Design $\mathrm{R}$ Value:

6. Method of Temperature Control:

7. Calibration Technique:

8. Specimen Fixture Configuration:
Owens-Corning Fiberglas Corp.

Mr. John Mumaw

$14 \times 20$ feet

Cold Side $\quad-50$ to $150^{\circ} \mathrm{F}$

Hot Side

15 to $145^{\circ} \mathrm{F}$

1 to $40^{+}$

Cold side - refrigeration unit

with SCR control on electric heaters. Hot Side - on/off control -

thermometer sensor with electrical

heater or brine system refrigeration

Measure a shell coefficient and a frame coefficient so that:

$$
\begin{aligned}
& Q_{\text {LOSS }}=C_{1}\left(T_{\text {HOT }}-T_{A M B}\right)+C_{2} \\
& \left(T_{\text {HOT }}-T_{\text {COLD }}\right)
\end{aligned}
$$

Specimen layed on end of bottom box for support. The specimen is in a frame with a 1/16" FRP skin. 
1. Organization:

2. Contact Person:

3. Test Specimen Size:

4. Temperature Range:

5. Design $R$ Value:

6. Method of Temperature Control:

7. Calibrated Technique:

8. Specimen Fixture Configuration:
Jim Walter Research Corporation

Dr. Gerry Miller

$8 \times 8$ feet ( $6 \times 6$ feet in Guarded Mode)

cold side $\quad-20$ to $80^{\circ} \mathrm{F}$

Hot Side $\quad 70$ to $160^{\circ} \mathrm{F}$

20

Cold side - refrigeration unit which supplies cold air. Controlled electrical heaters are used for fine tuning the temperature.

Hot Side - SCR controlled electrical heaters (three) in the box with a Leed and Northrup control unit.

Measure a shell coefficient and a frame coefficient so that:

$Q_{\text {LOSS }}=C_{1}\left(T_{\text {Hot }}-T_{A M B}\right)+$

$\mathrm{C}_{2}\left(\mathrm{~T}_{\text {Hot }}-\mathrm{T}_{\mathrm{Cold}}\right)$

Specimen is built into frame inside a $1 / 2 "$ plywood skin.

NOTE: The test section may be positioned vertically or horizontally and can be operated in the Guarded Mode. 
1. Organization:

2. Contact Person:

3. Specimen Size:

4. Temperature Range:

5. Design $R$ Value:

6. Method of Temperature Control:

7. Calibration Technique:

8. Specimen Fixture Configuration:
National Bureau of Standards

Mr. Frank Powe11

$10^{\prime}$ by $15^{\prime}$

Cola side -40 to $150^{\circ} \mathrm{F}$

Hot Side

50 to $150^{\circ} \mathrm{F}$

2 to 50

Cold Side - Refrigeration unit with $\mathrm{SCR}$ to control electric resistance heaters. Hot Side - Laboratory water supply and SCR to control electric resistance heaters.

Heat flow meters to measure metering chamber wall heat transfer to water jacket. Determine thermal resistance of calibration wall from Guarded

Hot Plate tests of material. Determine flanking heat transfer coefficient by difference.

Frame lining will be plywood or FRP. Specimen will be gasketed, caulked, or taped at perimeter to eliminate leakage.

NOTE: This facility has the ability to test under dynamic conditions with a maximum rate of change of $200 \mathrm{~F} / \mathrm{hr}$ at $82^{\circ} \mathrm{F}$. This facility is in the construction stage and will be ready for operation about spring, 1982. 
NBS/DOE WORKSHOP ON CALIBRATED HOT BOXES

MARCH $30, \quad 1979$

NBS - GAITHERSBURG

P.R. Achenbach

NBS - 740

Washington, DC 20234

301/921-3106

Michael Argie

Smith, Hinchman \& Grylls

$455 \mathrm{~W}$. Fort Street

Detroit, Michigan 48226

313/964-1000

Erv Bales - Workshop Chairman M.E. Department

Stevens Institute of Tech. Hoboken, New Jersey 07030

$201 / 273-2574$

Donald K. Baxter

U.S. Department HUD

451-7th Street, SW

Washington, DC 20410

202/755-5930

D.M. Burch

NBS - 742

Washington, DC 20234

$301 / 921-3501$

G.A. Berman

NBS - 782

washington, DC 20234

$301 / 921-2427$

W.L. Carroll (NBS-742)

Lawrence Berkeley Laboratory

Energy-Efficient Bldgs. Pgm

Berkeley, California

415/486-6651

S.C. Dangel

Dynatech R/D Company

99 Erie Street

Cambridge, MA 02139

617/868-8050
Andre' Desjarlais

Dynatech R/D Company

99 Erie Street

Cambridge, MA 02139

$617 / 868-8050 \times 270$

Merv W. Dizenfeld

U.S. Department HUD

451-7th street, SW

washington, DC 20410

202/755-6590

C. Donaldson

Division of Energy and Product

Information

Federal Trade Commission

7313 Star Building

Washington, DC 20580

202/724-1537

Anthony E. Fiorato

Portland Cement Association

5420 Old Orchard Road

Skokie, Illinois 60077

312/966-6200

J.B. Funkhouser

Dynatherm Engineering

595 Marshan Lane

Lino Lakes, MN 55014

612-786-1853

C.F. Gilbo

Consultant

201 East Ross Street,

Lancaster, Pennsylvania 17602

717/392-0520

D. Greason

Dow Chemical, USA

Granville Research Center Bldg. F P.O. Box 515

Granville, Ohio 43023

614/587-4362 
M.H. Hahn

Dennis Industries

19444 St. Johnsbury Lane

Germantown, MD 20757

$301 / 428-0471$

M. Hollingsworth

Owens/Corning Fiberglas

P.O. Box 415

Granville, Ohio 43023

614/587-0610

J.W. Howanski

W.R. Grace Company

Construction Products Div.

62 Whittemore Avenue

Cambridge, MA 02140

R.R. Jones

NBS - 742

Washington, DC 20234

$301 / 921-3637$

J.F. Kimpflin

Certain Teed Corporation

Valley Forge, PA 19481

$215 / 687-5000 \times 7526$

Diana Kj.rkpatrick

NBS - 782

Washington, DC 20234

$301 / 921-2946$

H.N. Knickle

Department of Chem. Eng.

University of R.I.

Kingston, RI 02881

401/792-2655

Stephen Lane

NBS - Rm B25 Bldg. 225

Washington, DC 20234

301/921-3481

W. C. Louie

Smith, Hinchman \& Grylls

$455 \mathrm{~W}$. Fort Street

Detroit, MI 48226

313/954-3000
H.H. Mackey, Jr.

U.S. Department of HUD

415-7th street, SW

washington, DC 20410

202/755-5929

D.J. McCaa

Certain Teed Corporation

1400 Union Meeting Road

Blue Bell, PA 19422

215/542-0500

Michael McCabe

NBS - 742

Washington, DC 20234

$301 / 921-3871$

P.E. MCNall

NBS - 742

Washington, DC 20234

$301 / 921-3637$

R.G. Mj.ller

Jim Walter Research Corporation

j.0301-9th Street, North

St. Petersburg, Florida 33702 813/576-4171

J.W. Murnaw

Owens/Corning Fiberglas

P.O. Box 415

Granville, Ohio 43023

614/587-0610

Henry Omson

Radco, Incorporated

218 North Lee Street

Alexandria, Virginia 22314

$703 / 836-2527$

B.A. Peavy

NBS - 742

Washington, DC 20234

$301 / 921-3501$

C.M. Pelanne

Johns Manville $\mathrm{R} / \mathrm{D}$

P.O. Box 5108

Denver, Colorado 80217

303/979-1000 
E.L. Perrine

Wiss, Janney, Elstner \& Assoc. 330 pfingsten Road

Northbrook, Illinois 60062 $312 / 272-7400$

F.J. Powell

NBS -. 790

Washington, DC 20234

30 I./921-3275

Edwin Randall

NES - 782

washington, DC 20234

$301 / 921-2946$

B. Rennex

NAHB Research Foundation

627 Southlawn Lane

P.O. Box 1627

Rockville, Maryland 20850

301/762-4201

Mary Reppert

NBS - 742

Washington, DC 20234

$301 / 921-3637$

Ben Reznels (NBS Consultant)

3501 Forest Edge Drive,

Unit 14-2G

Silver Spring, MD 20906

James iv. Robinson

Oak Ridge National Lab.

Energy Division

P.O. Box X

Oak Ridge, TN 37830

$615 / 574-5208$

Glen Schuyler

$\mathrm{NBC}-\mathrm{CANADA}$

C. Seal

Reynolds Metal Company

Williansburg Road \& Goddin st.

Richmond, Virginia 23235

804/788-7357
Mort Sherman

Jim Walter Research Corporation

1030l-9th Street, North

St. Petersburg, Florida 33702

$813-576-4171$

Marvin K. Snyder

Butler Manufacturing Company

Research Center

135th and Botts Road

Grandview, Missouri 64030

816/648-4009

Henry Taylor

Architectural Testing, Inc.

1360 North George Street

York, PA 17404

$717 / 846-7700$

Ron P. Tye

Dynatech R/D Company

99 Erie street

Cambridge, MA 02139

617/868-8050

Foster Wilson

Owens/Corning Fiberglas Corp.

Technical Center

P.O. Box 415

Granville, OHIO 43023

614/587-0610

Mike Zieman

RADCO, Incorporated

P.O. Box 5506

Carson, California 90749

$215 / 532-3842$ 


\section{APPENDIX 5 \\ PARALLEL HEAT FLOW FLANKING}

For a $1 / 2$ inch frame of plywood around a test specimen the ratio of areas would be:

$$
\frac{\text { Aspecimen }}{\text { Aplywood }}=\frac{H W}{2 t(H+W)+4 t^{2}}
$$

where the terms are defined by a sketch:

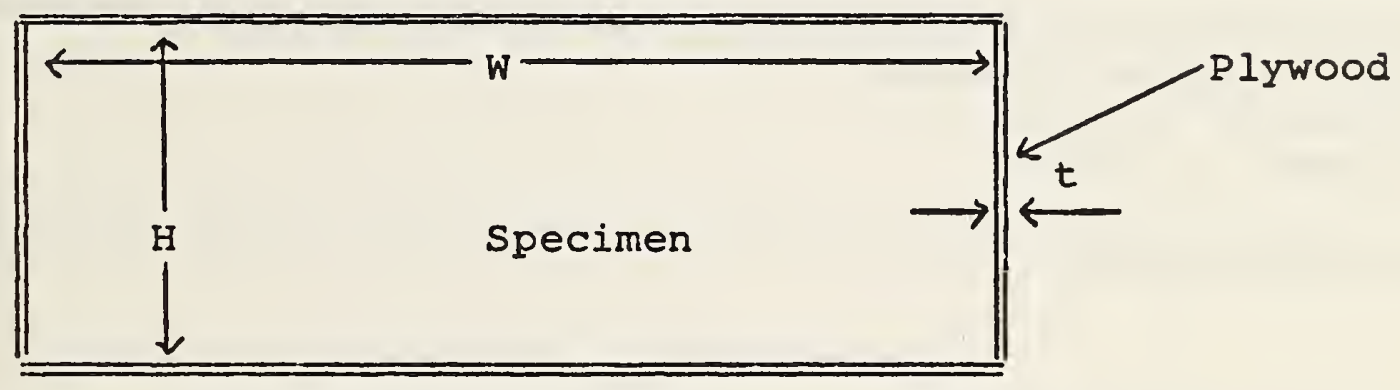

The ratio of the heat transfer through the two materials is, neglecting terms of $t^{2}$ :

$$
\frac{Q_{p}}{Q_{p}+Q_{s}}=\frac{U_{p} A_{p}}{U_{s} A_{s}}=\frac{R_{s}}{R_{p}} \frac{A_{p}}{A_{s}}
$$

For $H=10$ feet, $W=14$ feet, $t=1 / 2$ inch, and

$R_{s}=15$, and $R_{p}=1.25(3)$, where the insulation is

assumed to be 3 inches thick,

$$
\frac{Q_{p}}{Q_{s}}=.054
$$


NBS-114A (REV. 2.80)

U.S. DEPT, OF COMM.

1. PUBLICATION OR REPORT NO.

BIBLIOGRAPHIC DATA

SHEET (See instructions)

NBSIR 81-2443

2. Performing Organ. Report No. 3. Publication Date

February 1982

4. TITLE AND SUBTITLE

"Plan for a Round Robin of Hot Boxes"

5. AUTHOR(S)

Dr. Ervin L. Bales

6. PERFORMING ORGANIZATION (If joint or other than NBS, see in structions)

7. Contract/Grant No.

NATIONAL BUREAU OF STANDARDS

DEPARTMENT OF COMMERCE

8. Type of Report \& Period Covered

WASHINGTON, D.C. 20234

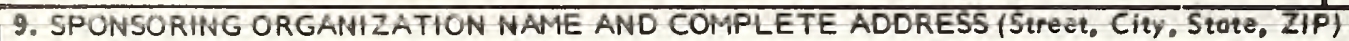

Final

National Bureau of Standards

Department of Conmerce

Washington, DC 20234

10. SUPPLEMENTARY NOTES

Document describes a computer program; SF-185, FIPS Software Summary, is attached.

11. ABSTRACT (A 200-word or less factual summary of most significant information. If document includes o signlficant bibliography or literature survey. mention it here)

A plan for an interlaboratory round robin series of tests sponsored by the American Society for Testing and Materials (ASTM) using calibrated or guarded hot-box equipment is described. These testing methods are designed to measure the thermal conductance of full-scale building sections such as walls, roofs and floors. Results from about 25 hot boxes in the U.S. and Canada are expected to produce improved calibration techniques and repeatability and uncertainty information useful for improving ASTM specifications.

12. KEY WORDS (Six to twelve entries; alphabetical order; capitalize only proper names; and separate key words by semicolons) interlaboratory round robin-tests, calibrated and guarded hot boxes, ASTM C-236, thermal conductance of building sections

13. AVAILABILITY

XX Unlimited

$\square$ For Official Distribution. Do Not Release' to NTIS

Order From Superintendent of Documents, U.S. Government Printing Office, Washington, D.C. 20402.

14. NO. OF

PRINTED PAGES

37

15. Price

XXOrder From National Technical Information Service (NTIS), Springfield, VA. 2216I

$\$ 7.50$ 
